\title{
Separation and Identification of HSP-Associated Protein Complexes from Pancreatic Cancer Cell Lines Using 2D CN/SDS-PAGE Coupled with Mass Spectrometry
}

\author{
Zhiyun Zhao, Hui Liu, Xinli Wang, Xiaodong Wang, and Zhili Li \\ Department of Biophysics and Structural Biology, Institute of Basic Medical Sciences, Chinese Academy of Medical Sciences and School \\ of Basic Medicine, Peking Union Medical College, Beijing 100005, China \\ Correspondence should be addressed to Zhili Li, lizhili@ibms.pumc.edu.cn
}

Received 16 May 2011; Revised 12 August 2011; Accepted 17 August 2011

Academic Editor: Kapil Mehta

Copyright ( $) 2011$ Zhiyun Zhao et al. This is an open access article distributed under the Creative Commons Attribution License, which permits unrestricted use, distribution, and reproduction in any medium, provided the original work is properly cited.

Protein complexes are a cornerstone of many biological processes and together they form various types of molecular machinery. A broad understanding of these protein complexes is crucial for revealing and building models of protein function and regulation. Pancreatic cancer is a highly lethal disease which is difficult to diagnose at early stage and even more difficult to cure. In this study, we applied a gradient clear native gel system combined with subsequent second-dimensional SDS-PAGE to separate protein complexes from cell lysates of SW1990 and PANC-1 pancreatic cancer cell lines with different degrees of differentiation. Ten heat-shock-protein- (HSP-) associated protein complexes were separated and identified, and the differentially expressed proteins related to cancers were also found, such as HSP60, protein disulfide-isomerase A4 (ERp72), and transitional endoplasmic reticulum ATPase (TER ATPase).

\section{Introduction}

Most proteins exert their functions by stable or transient interactions with other proteins either as homo- or heterooligomeric protein complexes $[1,2]$. The diversity of biological processes is derived from the dynamic network of protein interactions in cell. These interactions form the basis of the quaternary structure of multimeric proteins and represent one of the most complex levels of structural organization in biological molecules $[3,4]$. A broad understanding of protein complexes and protein interactions is crucial for revealing and building models of protein function and regulation.

A variety of approaches were used to study proteinprotein interactions, such as tandem affinity purification (TAP) [5], coimmunoprecipitation (co-IP) [6], yeast twohybrid assay [7], blue/clear (colorless) native PAGE (BN/CNPAGE) [8], and other gel approaches [9]. Among these methods, BN/CN-PAGE is widely used [2] and CN-PAGE is milder than BN-PAGE and offers special advantages for in-gel catalytic activity assays and analyses of fluorescentlabeled proteins $[10,11]$. After BN/CN-PAGE, a second-dimensional SDS-PAGE can be performed to separate polypeptides as components of protein complexes [12]. Previous studies using BN/CN-PAGE approach mainly focused on membrane, chloroplast, mitochondria, and plasma protein complexes [13-18]. So far, limited studies were associated with the protein complexes from cell lysate $[19,20]$.

Pancreatic cancer is a malignant neoplasm of the pancreas. During the past four decades, the incidence of pancreatic cancer has risen steadily [21]. The prognosis is relatively poor with less than $5 \%$ five-year survival rate, and complete remission is rare [22].

Heat shock proteins (HSPs) are a highly conserved family of proteins among living organisms during evolution [23]. A cell may have a variety of HSPs in cellular compartments such as endoplasmic reticulum, mitochondria, and cytosol [24]. HSPs have multiple functions such as proper folding of nascent chains, protein translocation across membranes, protein disaggregation, preservation and restructuring of the 
cytoskeleton, and targeting damaged proteins for degradation $[24,25]$. HSPs may serve as potential molecular targets for therapeutic intervention in the treatment of diseases, such as cancer, Alzheimer's, and Parkinson's diseases [26]. The heat shock protein peptide complex-96-based vaccines in melanoma were also tested in phase III clinical trials in melanoma and kidney cancer [27]. In pancreatic cancer, it was found that HSP70 and HSP90 were overexpressed [2830].

In this study, we applied a gradient clear native gel followed by a second-dimensional SDS-PAGE to reveal the HSP-associated protein complexes from the cell lysates of SW1990 and PANC-1 pancreatic cell lines. The components of these complexes were then identified by MALDI-MS and MS/MS.

\section{Materials and Methods}

2.1. Materials and Chemicals. Protease inhibitor cocktail tablets were obtained from Roche Applied Science (Indianapolis, Ind, USA). Sequencing-grade trypsin was purchased from Roche diagnostics (Mannheim, Germany). $\alpha$-cyano-4hydroxycinnamic acid (CHCA) was from Sigma-Aldrich (St. Louis, Mo, USA). All other chemicals were obtained from Merck (Darmstadt, Germany).

2.2. Sample Preparation. PANC-1 and SW1990 were cultured in Dulbecco's Modified Eagle's medium (DMEM) and RPMI-1640 medium, respectively, supplemented with 10\% fetal calf serum and $100 \mathrm{U} / \mathrm{mL}$ penicillin/streptomycin at $37^{\circ} \mathrm{C}$ and $5 \% \mathrm{CO}_{2}$ in a humidified atmosphere.

After harvested cells were washed with PBS, the cells were lysed by three-cycle liquid $\mathrm{N}_{2} / 4^{\circ} \mathrm{C}$ in lysis buffer $(50 \mathrm{mM}$ Tris- $\mathrm{HCl}, \mathrm{pH} 7.5,5 \mathrm{mM} \mathrm{MgCl} 2,150 \mathrm{mM} \mathrm{NaCl}, 0.05 \%$ NP40, $1 \mathrm{mM}$ DTT, $2 \times$ Roche protease inhibitor cocktail, $10 \mathrm{mM}$ sodium fluoride, and $10 \mathrm{mM}$ sodium pyrophosphate). The lysate was centrifuged at $20,000 \mathrm{xg}$ for $60 \mathrm{~min}$ at $4^{\circ} \mathrm{C}$. The supernatant containing protein complexes was centrifuged again at $10,000 \mathrm{xg}$ for $30 \mathrm{~min}$ at $4^{\circ} \mathrm{C}$ for at least three times to remove the lipids in the lysate. The protein concentration was determined by Bradford assay using bovine serum albumin as the standard protein.

2.3. Separation of HSP-Associated Protein Complexes. CNPAGE was performed based on previous protocols [31, 32]. $100 \mu \mathrm{g}$ of proteins was loaded onto the gel. CN-PAGE was performed with $4 \%$ stacking gel and $6 \%, 5-10 \%$ or $5-12 \%$ separating gel with $13 \mathrm{~cm}$ casting gel system, respectively. GE Healthcare HMW-Native protein markers (GE Healthcare, Uppsala, Sweden) were used. The gel was run at $4^{\circ} \mathrm{C}$ until the xylene cyanol reached the gel bottom.

\subsection{Separation of the Components of HSP-Associated Protein} Complexes. For further separation in subsequent seconddimensional SDS-PAGE, the protein complex bands or the whole lanes from CN-PAGE were cut out and equilibrated for $20 \mathrm{~min}$ in equilibrating buffer A containing $62.5 \mathrm{mM}$ Tris- $\mathrm{HCl}$ pH $6.8,2 \%$ SDS, $10 \%$ glycerol, and 1\% DTT. The bands or lanes were then dipped into equilibrating buffer B supplemented with $62.5 \mathrm{mM}$ Tris- $\mathrm{HCl} \mathrm{pH} \mathrm{6.8,} \mathrm{2 \%} \mathrm{SDS,}$ $10 \%$ glycerol, and $2.5 \%$ iodoacetamide for $20 \mathrm{~min}$ at room temperature. The bands or lanes were washed with deionized water followed by 12\% SDS-PAGE separation. Gels were stained with Coomassie blue G-250.

2.5. In-Gel Digestion and Protein Identification. Protein bands or spots from the second-dimensional SDS-PAGE were excised and cut into small pieces. After destained, reduced, and alkylated, the gel pieces were dehydrated in acetonitrile and covered by some volume of $12.5 \mathrm{ng} / \mu \mathrm{L}$ trypsin in $25 \mathrm{mM}$ ammonium bicarbonate for $1 \mathrm{~h}$ at $4^{\circ} \mathrm{C}$. Protein digestion was performed for overnight at $37^{\circ} \mathrm{C}$.

$1 \mu \mathrm{L}$ of the digest was spotted onto an MTP AnchorChip $384 / 400$ plate and dried at room temperature before the addition of $1 \mu \mathrm{L}$ matrix solution of $1 \mathrm{mg} / \mathrm{mL}$ CHCA in $33 \%$ ACN $/ 0.1 \%$ TFA. After the mixtures were completely dried at room temperature, the AnchorChip was delivered into autoflex III MALDI-TOF/TOF MS (Bruker Daltonics, Billerica, Mass, USA). The mass spectrometer was operated under $20 \mathrm{kV}$ accelerating voltage in the positive-ion reflectron mode with the mass range of $\mathrm{m} / \mathrm{z} 800-4000$.

The monoisotopic peptide mass was generated by Flexanalysis 3.0 (Bruker Daltonics), and the database search was performed by Biotools 3.1 software (Bruker Daltonics) against Swiss-Prot database using the MASCOT search algorithm. The parameters are as follows: one missed tryptic cleavage; taxonomy: Homo sapiens; carbamidomethylation of cysteine as fixed modification; oxidation of methionine and $\mathrm{N}$-terminal pyroglutamylation as variable modifications; mass tolerance: $0.1 \mathrm{Da}$ for precursor ions and $0.5 \mathrm{Da}$ for product ions. Results were considered as significant with MASCOT score higher than $60(P<0.05)$. Sequence coverage, number of matched MS/MS, and the experimental molecular weight based on SDS-PAGE were also used to confirm further identification.

2.6. Protein-Protein Interaction Analysis. A protein-protein interaction network of the proteins identified in the HSPassociated complexes was created using STRING database (http://string-db.org/) through inputting the Swiss-Prot accession numbers.

\section{Results and Discussion}

3.1. Separation of Protein Complexes by CN-PAGE. Due to the aberrant effect of hydrophobic lipids in lysate on CNPAGE performance, several approaches have been tried and finally the centrifugation was chosen to remove lipids. It should be noted that at least three-time centrifugations were needed for complete removal of lipids. To establish the conditions of CN-PAGE for adequately resolving protein complexes, three separating gels were tried: $6 \%$ nongradient (left, Figure 1(a)), 5-10\% gradient (middle, Figure 1(a)) and $5-12 \%$ gradient gels (right, Figure 1(a)). As shown in Figure 1(a), protein complexes were well separated on $5-12 \%$ gradient gel compared to nongradient and $5-10 \%$ gel. 


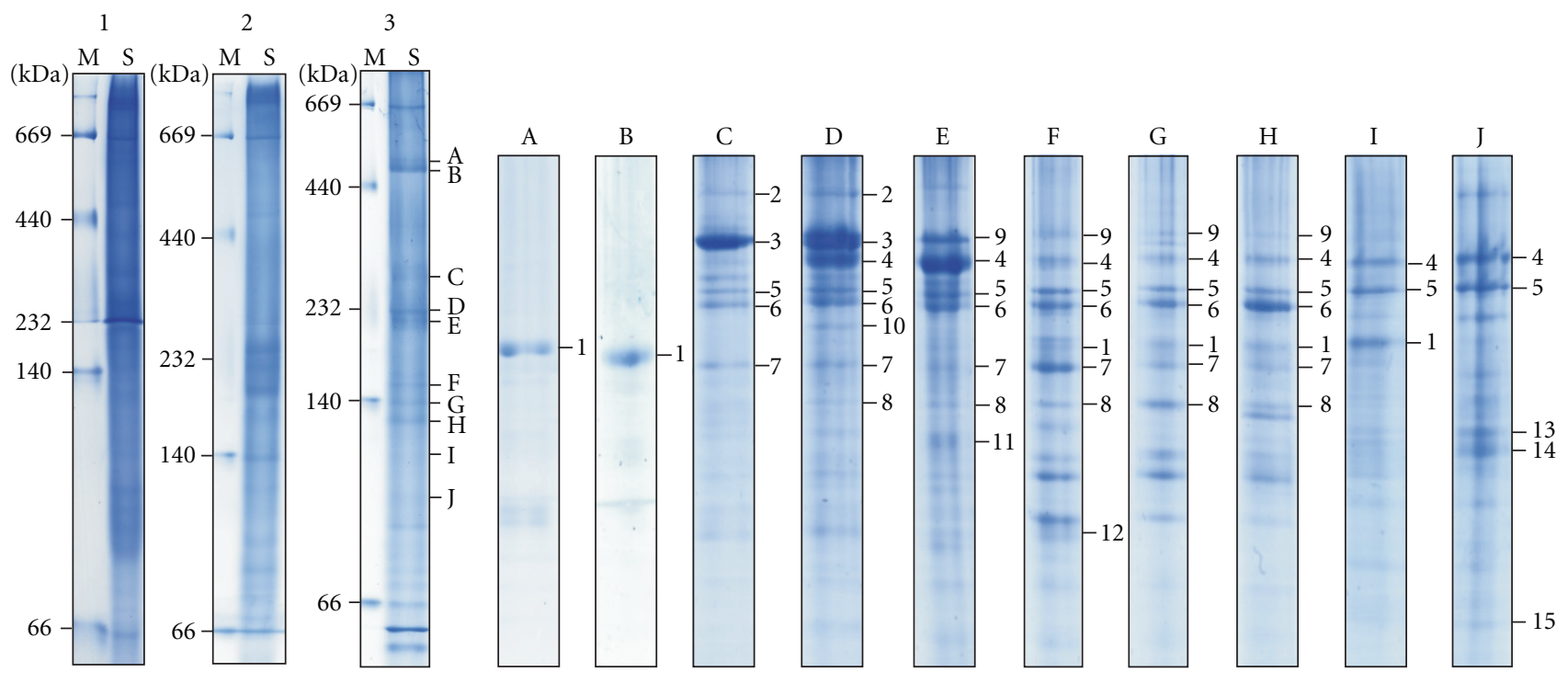

(a)

(b)

Figure 1: 6\% (1), 5-10\% (2), and 5-12\% (3) separating gels were used to separate the protein complexes from SW1990 cell lysate. M: GE Healthcare HMW-Native protein markers; S: cell lysate of SW1990 (a). SDS-PAGE of ten protein complexes labeled with A-J from 5-12\% CN-PAGE. At least two-band combination of each complex was used to run SDS-PAGE (b).

TABLE 1: Identification results of HSP-associated protein complexes.

\begin{tabular}{lccccccc}
\hline C & D & E & F & G & H & I & J \\
\hline ORP-150 & ORP-150 & Alpha-actinin-4 & Alpha-actinin-4 & Alpha-actinin-4 & Alpha-actinin-4 & - & - \\
- & HSP90 & HSP90 & HSP90 & HSP90 & HSP90 & HSP90 & HSP90 \\
- & HSP90-beta & HSP9-beta & HSP90-beta & HSP90-beta & HSP90-beta & HSP90-beta & HSP90-beta \\
BiP & BiP & BiP & BiP & BiP & BiP & BiP & BiP \\
HSP71 & HSP71 & HSP71 & HSP71 & HSP71 & HSP71 & - & Beta-actin \\
ERp57 & ERp57 & ERp57 & ERp57 & ERp57 & ERp57 & - & Gamma-actin \\
- & ERp5 & ERp5 & ERp5 & ERp5 & ERp5 & - & PGAM-B \\
GRP-94 & GRP-94 & SAHase & HSP60 & HSP60 & HSP60 & HSP60 & - \\
- & NAD-ME & - & LDH-A & - & - & - & - \\
\hline
\end{tabular}

3.2. Identification and Interaction Analysis of HSP-Associated Protein Complexes. The protein complexes in the CN-PAGE (right, Figure 1(a)) were individually separated by seconddimensional SDS-PAGE (Figure 1(b)). The bands in the SDS-PAGE were excised, digested, and identified by MALDIMS and MS/MS. The identified proteins are listed in Table S1 and their corresponding MASCOT score, sequence coverage, and number of matched MS/MS are also listed in Table S1 (see Table S1 in supplementary material available online at doi:10.1155/2011/193052). The components of each complex are shown in Table 1.

The apparent masses of complex A and B are about $470 \mathrm{kDa}$ (right, Figure 1(a)), and the components of both complexes were identified as HSP60 (band 1, Figure 1(b)). A previous study showed that the HSP60 complex is a homoheptamer with apparent mass of $420 \mathrm{kDa}$ in BN-PAGE [33]. The mass difference may be due to the fact that the $\mathrm{CN}$ PAGE migration distance depends on not only the pore size of gradient gel but also the protein intrinsic charge and size, while the BN-PAGE migration distance depends only on the pore size of the gel.

For complex $\mathrm{C}$, the most intensively stained protein was identified as endoplasmin (GRP-94) (band 3, Figure 1(b)), which is involved in the processing and transporting of secreted proteins [34]. The other proteins are hypoxia upregulated protein 1 (ORP-150), $78 \mathrm{kDa}$ glucose-regulated protein (BiP), HSP71, and protein disulfide-isomerase A3 (ERp57) (Table 1). GRP-94, OPR-150, and BiP are glucoseregulated proteins. GRP-94 and $\mathrm{BiP}$ are also members of the 90 and $70 \mathrm{kDa}$ families of HSPs, and OPR-150 is a large HSP70-, HSP110-like protein of the endoplasmic reticulum [35]. HSP71 belongs to the heat shock protein 70 family. ERp57 is a member of the protein-disulfide-isomerase(PDI-) like family, and it has been implicated in human pathologies including cancer and Alzheimer's disease [36].

In addition to the proteins identified in complex $\mathrm{C}$, four other proteins were identified in complex D. They are heat shock protein HSP 90-alpha (HSP90), heat shock protein 


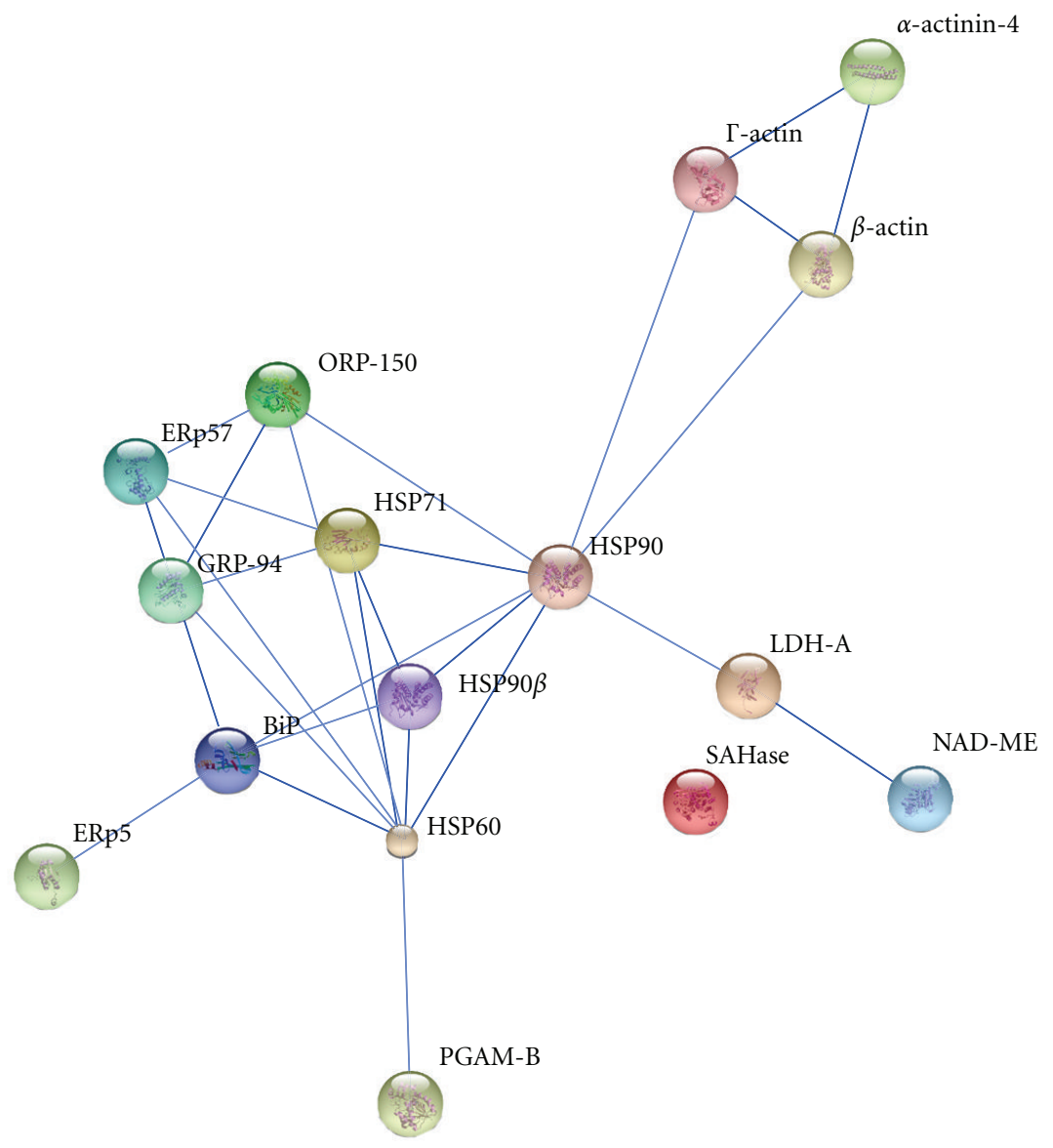

(a)

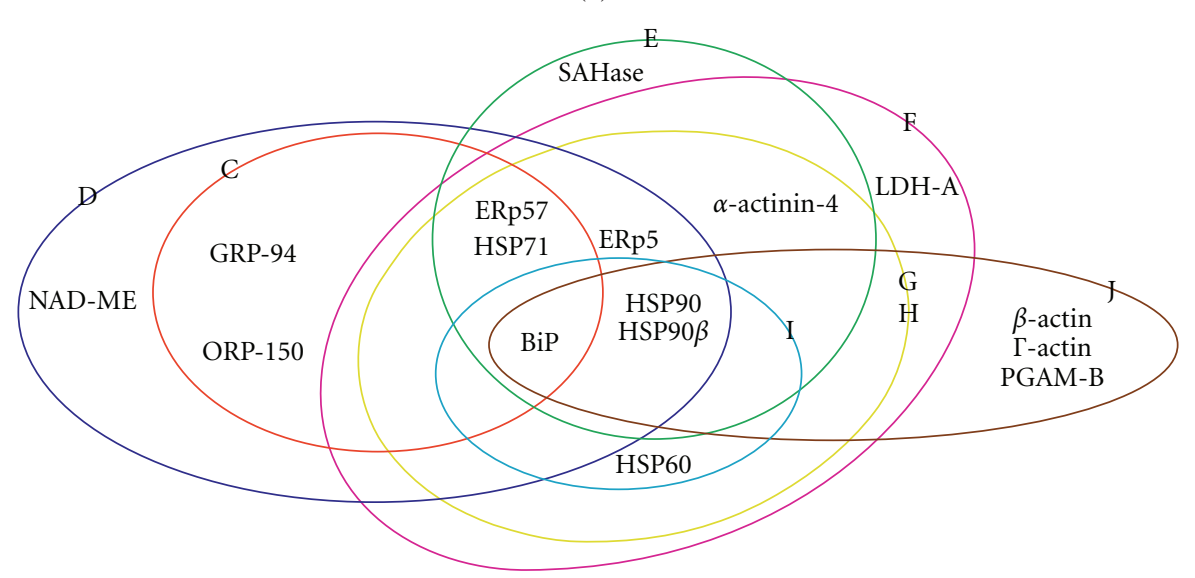

(b)

FIGURE 2: Interaction analysis of proteins from the HSP-associated complexes using the STRING database. The lines represent interactions and individual proteins are depicted as nodes. Stronger interactions are represented by thicker lines (a). The HSP-associated complexes from this study are shown in different ellipses. The sign of each protein complex is indicated on the edge of each ellipse (b).

HSP90-beta (HSP90-beta), protein disulfide isomerase P5 (ERp5), and NAD-dependent malic enzyme (NAD-ME). HSP90 and HSP90-beta belong to the heat shock protein 90 family. HSP90 proteins play essential housekeeping functions, and they are used by cancer cells to facilitate the function of numerous oncoproteins $[37,38]$. ERp5 as a member of the protein-disulfide-isomerase- (PDI-) like family was found to interact with BiP [39]. NAD-ME plays an important role in the metabolism of glutamine for energy production in rapidly proliferating tissues and tumors [40]. 


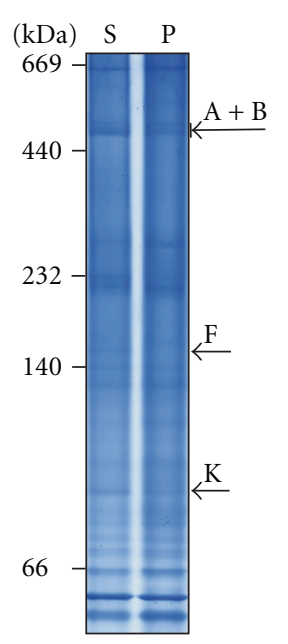

(a)
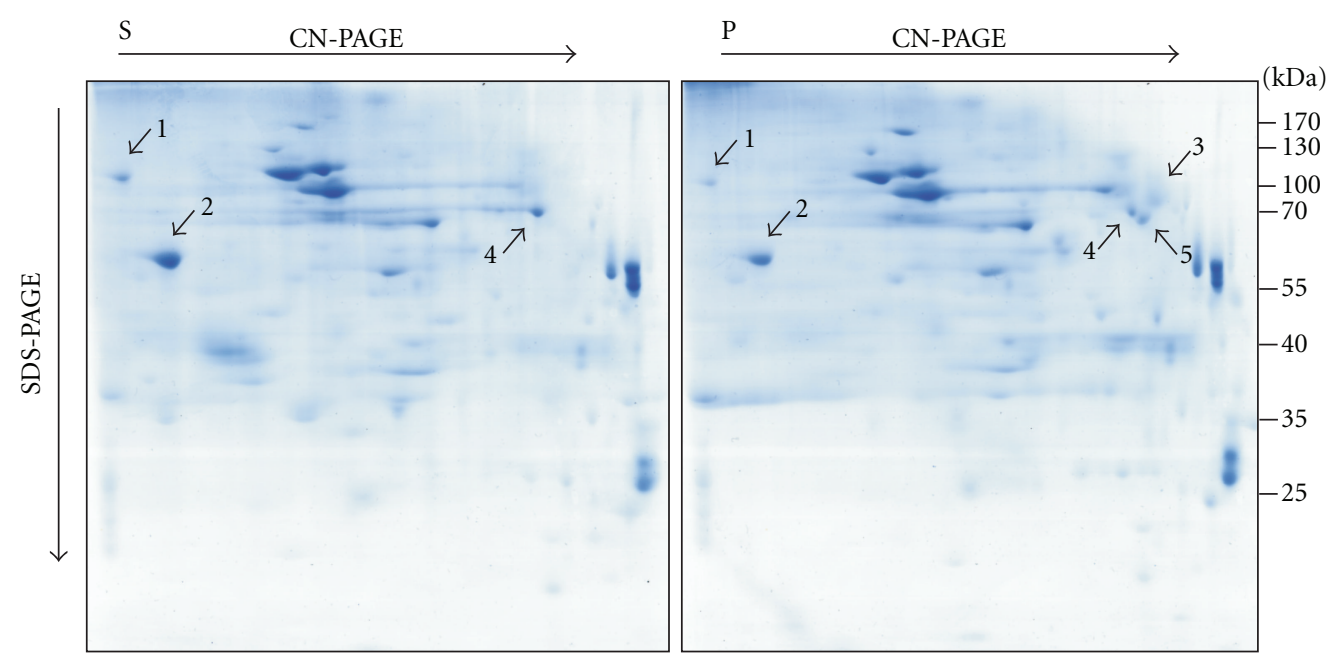

(b)

FIGURE 3: The protein complexes differentially expressed between SW1990; and PANC-1 cell lines were labeled by A+B, F, and K in CNPAGE (a). The proteins differentially expressed between two cell lines in the second-dimensional SDS-PAGE were labeled in number (b) S: cell lysate of SW1990; P: cell lysate of PANC-1.

TABLE 2: Differential protein complexes and differential proteins between SW1990 and PANC-1 cell lines.

\begin{tabular}{lc}
\hline $\begin{array}{l}\text { Complex (fold change SW1990 } \\
\text { to PANC-1) in Figure 3(a) }\end{array}$ & $\begin{array}{c}\text { Spot number (protein name; fold } \\
\text { change SW1990 to PANC-1) in } \\
\text { Figure 3(b) }\end{array}$ \\
\hline $\begin{array}{l}\text { Complex (A+B) (1.61) } \\
\text { Complex K (1.96) }\end{array}$ & $2($ HSP60; 1.85) \\
Complex F (found only in \\
SW1990)
\end{tabular}

The proteins identified in complex $\mathrm{E}$ are alpha-actinin-4, HSP90, HSP90-beta, BiP, HSP71, ERp57, ERp5, and adenosylhomocysteinase (SAHase). Except alpha-actinin-4 and SAHase, the rest also were found in the complex D. Alphaactinin-4 regulates the actin cytoskeleton and is associated with cell motility and cancer invasion [41]. SAHase may play a key role in the control of methylations via regulation of the intracellular concentration of adenosylhomocysteine [42].

The identified components of complexes of $F, G$, and $\mathrm{H}$ are similar. Alpha-actinin-4, HSP90, HSP90-beta, BiP, HSP71, ERp57, ERp5, and HSP60 were found in these three complexes. It should be noted that HSP60 presents in these three complexes, although not in the complexes of C, D, and E. HSP60 is a molecular chaperone known to assist protein folding in prokaryotes and in eukaryotic cell organelles. Its roles in human cancer development are currently actively being investigated [43].

The identified components of complex I are HSP90, HSP90-beta, BiP, and HSP60, and the identified components of complex J are HSP90, HSP90-beta, BiP, beta-actin, gamma-actin, and phosphoglycerate mutase 1 (PGAM-B). Actin is one of the most highly conserved proteins. The beta- and gamma-actins co-exist in most cell types as components of the cytoskeleton and mediators of internal cell motility [44]. PGAM-B is a key enzyme of the glycolytic pathway, which converts 3-phosphoglycerate to 2-phosphoglycerate [45].

A network of the identified proteins in the HSP-associated complexes was obtained using the STRING software (Figure 2(a)). In this network all proteins interact with other proteins except SAHase. Previously, it was also found that HSP90, HSP70, and HSP60 interacted with each other in human cells $[19,46]$. The HSP-associated complexes were plotted in Figure 2(b). These complexes were shown in different ellipses, respectively, indicating that HSP90, HSP90-beta, and HSp71 are "hot" proteins in these complexes. The major HSPs have five conserved classes: HSP100, HSP90, HSP70, HSP60, and the small heat shock proteins (sHSPs) [47]. Each chaperone class displays relatively specialized functions but the members of different classes often work together to perform their duties in the form of larger multi-protein complexes $[24,48]$. Our results indicate that, in pancreatic cancer cells, HSP90, HSP90-beta, and HSP71 could form many different complexes with other proteins.

\subsection{Protein Complexes Expression Differences between} SW1990 and PANC-1 Cell Lines. SW1990 and PANC-1 are pancreatic cancer cell lines derived from pancreatic duct with different differentiation degrees. SW1990 is a well to moderately differentiated cell line established from a spleen metastasis of pancreatic duct cancer, and PANC-1 is a poorly differentiated cell line $[49,50]$. The spots with differential expression over 1.5-folds were regarded as candidates of differential expression, followed by MALDI-MS and MS/MS identifications (Table S2). 
The expression differences of the protein complexes labeled by A+B, F, and K between SW1990 and PANC-1 cell lines are shown in Figure 3(a), and differential expression proteins labeled in number are shown in Figure 3(b). Table 2 summarized the link between protein complexes in Figure 3(a) and spots in Figure 3(b) and also provided the fold changes of these complexes or individual protein between SW1990 and PANC-1 cell lines. Compared to PANC-1, the complexes $(\mathrm{A}+\mathrm{B})(\mathrm{A}+\mathrm{B}$ means the combination of complexes $\mathrm{A}$ and $\mathrm{B}), \mathrm{F}$, and $\mathrm{K}$ were upexpressed in SW1990 (Figure 3(a)). The expression trends of the complexes $(A+B)$ and $K$ in Figure $3(a)$ were in accordance with those of their components corresponding to spots 2 and 4, respectively (Figure 3(b)). The components of the complex F were not, however, enough in abundance to be observed in the SDS-PAGE. Additionally, TER ATPase (spot 1, Figure 3(b)), protein-glutamine gamma-glutamyltransferase 2 (transglutaminase-2, spot 3, Figure 3(b)), and annexin A6 (spot 5, Figure 3(b)) were obviously observed in the SDSPAGE.

As shown in Figure 3(b), TER ATPase (spot 1) with many important biological functions [51] was upexpressed in SW1990 cells, which is associated with intestinal tumorigenesis as indicated in previous study [52]. HSP60 (spot 2, Figure 3(b)) was upexpressed in SW1990 cells. Although the role of HSP60 in cancer has not been determined yet, upregulation or downregulation of this chaperone has been reported in various tumors, histopathological diagnosis and prognosis assessment [43, 53]. HSP60 was found to be downregulated in tumors compared with normal pancreas tissues in the 2-DE analysis; on the contrary, the data from immunohistochemistry showed that HSP60 was strongly expressed in both normal acinar cells and small ducts in normal pancreas tissues and tumor cells in all the pancreatic ductal adenocarcinoma tissues [54].

The complex F was found only in SW1990 cell lysate (Figure 3(a)). The difference of this HSP-associated complex in the two pancreatic cancer cells may suggest the importance of HSPs in cancers as other studies reported [23, 48].

The main function of transglutaminase-2 (spot 3, Figure $3(\mathrm{~b})$ ) is to catalyze the cross-linking of proteins and conjugating of polyamines to proteins, and its expression was elevated in most pancreatic ductal adenocarcinoma tumors and cell lines [55]. In melanoma, transglutaminase-2 absence in the host is a favoring condition for the formation and development of the metastasis, while the presence of transglutaminase- 2 in the tumor cells might be requested for the development of the metastasis [56], which is consistent with our finding of transglutaminase- 2 expression only in the poorly differentiated PANC-1 cells. Protein disulfideisomerase A4 (ERp72) (complex K, Figure 3(a); spot 4, Figure $3(\mathrm{~b})$ ) is another protein that was upexpressed in the well to moderately differentiated and metastatic SW1990 cell line. In hepatocellular carcinoma (HCC), the upregulation of ERp72 was discovered not only in highly metastatic HCC cell lines but also in highly metastatic and already metastasized HCC patient's sera [57]. Annexin A6 (spot 5, Figure 3(b)), which was upregulated in PANC-1 cells, regulates the release of $\mathrm{Ca}^{2+}$ from intracellular stores, and it displays tumor suppressor activity via facilitating the $\mathrm{Ca}^{2+}$-dependent membrane targeting of p120GAP to downregulate Ras activity [58].

\section{Conclusions}

In this study, protein complexes in SW1990 and PANC-1 cell lysates were separated and identified by 2D CN/SDS-PAGE coupled with mass spectrometry. Ten HSP-associated complexes were identified. Our study indicates that HSP90, HSP90-beta, and HSP71 may be "core" proteins in these complexes. The differentially expressed proteins such as HSP60, TER ATPase, and transglutaminase-2 also were profiled in SW1990 and PANC-1 cells, which are cancer-related proteins. It should be noted that the $2 \mathrm{D}$ CN/SDS-PAGE coupled with mass spectrometry strategy may be a simple and powerful tool to screen protein-protein interactions among different cell types and tissues.

\section{Abbreviations}

BN-PAGE: blue native PAGE.

CN-PAGE: clear (colorless) native PAGE.

HSP: heat shock protein.

HPRD: human protein reference database.

\section{Acknowledgments}

This investigation was supported by Grant 21075137 from the National Natural Science Foundation of China and Grant 2006AA02Z154 awarded by National High-Tech R\&D Program of China (863 Program). The authors have no conflict of interests to declare.

\section{References}

[1] M. Abu-Farha, F. Elisma, and D. Figeys, "Identification of protein-protein interactions by mass spectrometry coupled techniques," Advances in Biochemical Engineering/Biotechnology, vol. 110, pp. 67-80, 2008.

[2] F. Krause, "Detection and analysis of protein-protein interactions in organellar and prokaryotic proteomes by native gel electrophoresis: (Membrane) protein complexes and supercomplexes," Electrophoresis, vol. 27, no. 13, pp. 2759-2781, 2006.

[3] A. J. Link, T. C. Fleischer, C. M. Weaver, V. R. Gerbasi, and J. L. Jennings, "Purifying protein complexes for mass spectrometry: applications to protein translation," Methods, vol. 35, no. 3, pp. 274-290, 2005.

[4] R. P. Bahadur and M. Zacharias, "The interface of proteinprotein complexes: analysis of contacts and prediction of interactions," Cellular and Molecular Life Sciences, vol. 65, no. 7-8, pp. 1059-1072, 2008.

[5] X. Xu, Y. Song, Y. Li, J. Chang, H. Zhang, and L. An, "The tandem affinity purification method: an efficient system for protein complex purification and protein interaction identification," Protein Expression and Purification, vol. 72, no. 2, pp. 149-156, 2010. 
[6] E. A. Elion, "Detection of protein-protein interactions by coprecipitation," Current Protocols in Neuroscience, 2006, chapter 5, Unit 5.25.

[7] B. Suter, S. Kittanakom, and I. Stagljar, "Two-hybrid technologies in proteomics research," Current Opinion in Biotechnology, vol. 19, no. 4, pp. 316-323, 2008.

[8] I. Wittig and H. Schägger, "Native electrophoretic techniques to identify protein-protein interactions," Proteomics, vol. 9, no. 23, pp. 5214-5223, 2009.

[9] X. Wang, G. Chen, H. Liu, Z. Zhao, and Z. Li, "Four-dimensional orthogonal electrophoresis system for screening protein complexes and protein-protein interactions combined with mass spectrometry," Journal of Proteome Research, vol. 9, no. 10, pp. 5325-5334, 2010.

[10] I. Wittig and H. Schägger, "Advantages and limitations of clear-native PAGE," Proteomics, vol. 5, no. 17, pp. 4338-4346, 2005.

[11] I. Wittig and H. Schägger, "Features and applications of bluenative and clear-native electrophoresis," Proteomics, vol. 8, no. 19, pp. 3974-3990, 2008.

[12] F. Krause and H. Seelert, "Detection and analysis of proteinprotein interactions of organellar and prokaryotic proteomes by blue native and colorless native gel electrophoresis," Current Protocols in Protein Science, 2008, chapter 14, unit 14.11.

[13] V. Reisinger and L. A. Eichacker, "Analysis of membrane protein complexes by blue native PAGE," Proteomics, vol. 1, supplement 2, pp. 6-15, 2006.

[14] M. Kügler, L. Jänsch, V. Kruft, U. K. Schmitz, and H. P. Braun, "Analysis of the chloroplast protein complexes by blue-native polyacrylamide gel electrophoresis (BN-PAGE)," Photosynthesis Research, vol. 53, no. 1, pp. 35-44, 1997.

[15] L. G. J. Nijtmans, N. S. Henderson, and I. J. Holt, "Blue Native electrophoresis to study mitochondrial and other protein complexes," Methods, vol. 26, no. 4, pp. 327-334, 2002.

[16] P. S. Brookes, A. Pinner, A. Ramachandran et al., "High throughput two-dimensional blue-native electrophoresis: a tool for functional proteomics of mitochondria and signaling complexes," Proteomics, vol. 2, no. 8, pp. 969-977, 2002.

[17] T. Manabe and Y. Jin, "Noncovalent interactions in human plasma proteins analyzed by the comparison of nondenaturing and denaturing micro-2-D gel electrophoresis patterns after polypeptide assignment using matrix-assisted laser desorption/ionization-mass spectrometry and peptide mass fingerprinting," Electrophoresis, vol. 29, no. 12, pp. 2672-2688, 2008.

[18] S. Sunderhaus, H. Eubel, and H. P. Braun, "Two-dimensional blue native/blue native polyacrylamide gel electrophoresis for the characterization of mitochondrial protein complexes and supercomplexes," Methods in Molecular Biology, vol. 372, pp. 315-324, 2007.

[19] K. Liu, L. Qian, J. Wang et al., "Two-dimensional blue native/SDS-PAGE analysis reveals heat shock protein chaperone machinery involved in hepatitis $\mathrm{B}$ virus production in HepG2.2.15 cells," Molecular and Cellular Proteomics, vol. 8, no. 3, pp. 495-505, 2009.

[20] M. M. Camacho-Carvcajal, B. Wollscheid, R. Aebersold, V. Steimle, and W. W. A. Schamel, "Two-dimensional Blue Native/SDS gel electrophoresiss of multi-protein complexes from whole cellular lysates: a proteomics approach," Molecular and Cellular Proteomics, vol. 3, no. 2, pp. 176-182, 2004.

[21] A. Jemal, R. Siegel, E. Ward et al., "Cancer statistics, 2006," CA-A Cancer Journal for Clinicians, vol. 56, no. 2, pp. 106-130, 2006.
[22] P. Ghaneh, E. Costello, and J. P. Neoptolemos, "Biology and management of pancreatic cancer," Postgraduate Medical Journal, vol. 84, no. 995, pp. 478-497, 2008.

[23] V. Dudeja, S. M. Vickers, and A. K. Saluja, "The role of heat shock proteins in gastrointestinal diseases," Gut, vol. 58, no. 7, pp. 1000-1009, 2009.

[24] L. Tutar and Y. Tutar, "Heat shock proteins; An overview," Current Pharmaceutical Biotechnology, vol. 11, no. 2, pp. 216222, 2010.

[25] A. L. Joly, G. Wettstein, G. Mignot, F. Ghiringhelli, and C. Garrido, "Dual role of heat shock proteins as regulators of apoptosis and innate immunity," Journal of Innate Immunity, vol. 2, no. 3, pp. 238-247, 2010.

[26] V. V. Malaitsev, I. M. Bogdanova, and O. V. Makarova, "Heat shock proteins and their role in the development of pathological processes," Arkhiv Patologii, vol. 70, no. 6, pp. 3138, 2008.

[27] A. Di Pietro, G. Tosti, P. F. Ferrucci, and A. Testori, "Heat shock protein peptide complex 96-based vaccines in melanoma: how far we are, how far we can get," Human Vaccines, vol. 5, no. 11, pp. 727-737, 2009.

[28] Y. Oki and A. Younes, "Heat shock protein-based cancer vaccines," Expert Review of Vaccines, vol. 3, no. 4, pp. 403-411, 2004.

[29] A. Saluja and V. Dudeja, "Heat shock proteins in pancreatic diseases," Journal of Gastroenterology and Hepatology, vol. 23, supplement 1, pp. S42-S45, 2008.

[30] T. M. Gress, F. Müller-Pillasch, C. Weber et al., "Differential expression of heat shock proteins in pancreatic carcinoma," Cancer Research, vol. 54, no. 2, pp. 547-551, 1994.

[31] S. Elsasser, M. Schmidt, and D. Finley, "Characterization of the proteasome using native gel electrophoresis," Methods in Enzymology, vol. 398, pp. 353-363, 2005.

[32] G. Chen, Y. Luo, X. Wang et al., "A relatively simple and economical protocol for proteomic analyses of human $20 \mathrm{~S}$ proteasome: compatible with both scaled-up and scaled-down purifications," Electrophoresis, vol. 30, no. 14, pp. 2422-2430, 2009.

[33] N. H. Reifschneider, S. Goto, H. Nakamoto et al., "Defining the mitochondrial proteomes from five rat organs in a physiologically significant context using 2D blue-native/SDSPAGE," Journal of Proteome Research, vol. 5, no. 5, pp. 11171132, 2006.

[34] J. C. Christianson, T. A. Shaler, R. E. Tyler, and R. R. Kopito, "OS-9 and GRP94 deliver mutant $\alpha 1$-antitrypsin to the Hrd1?SEL1L ubiquitin ligase complex for ERAD," Nature Cell Biology, vol. 10, no. 3, pp. 272-282, 2008.

[35] X. Chen, D. Eastonb, H.-J. Oh, D.-S. Lee-Yoon, X. Liu, and J. Subjeck, "The $170 \mathrm{kDa}$ glucose regulated stress protein is a large HSP70-, HSP110-like protein of the endoplasmic reticulum," FEBS Letters, vol. 380, no. 1-2, pp. 68-72, 1996.

[36] H. Coe and M. Michalak, "ERp57, a multifunctional endoplasmic reticulum resident oxidoreductase," International Journal of Biochemistry and Cell Biology, vol. 42, no. 6, pp. 796-799, 2010.

[37] J. Trepel, M. Mollapour, G. Giaccone, and L. Neckers, "Targeting the dynamic HSP90 complex in cancer," Nature Reviews Cancer, vol. 10, no. 8, pp. 537-549, 2010.

[38] H. Hao, Y. Naomoto, X. Bao et al., "HSP90 and its inhibitors," Oncology Reports, vol. 23, no. 6, pp. 1483-1492, 2010.

[39] C. E. Jessop, R. H. Watkins, J. J. Simmons, M. Tasab, and N. J. Bulleid, "Protein disulphide isomerase family members show distinct substrate specificity: P5 is targeted to BiP client 
proteins," Journal of Cell Science, vol. 122, no. 23, pp. 42874295, 2009.

[40] Z. Yang, C. W. Lanks, and L. Tong, "Molecular mechanism for the regulation of human mitochondrial $\mathrm{NAD}(\mathrm{P})+-$-Dependent malic enzyme by ATP and umarate," Structure, vol. 10, no. 7, pp. 951-960, 2002.

[41] K. Honda, T. Yamada, R. Endo et al., "Actinin-4, a novel actin-bundling protein associated with cell motility and cancer invasion," Journal of Cell Biology, vol. 140, no. 6, pp. 13831393, 1998.

[42] X. Yang, Y. Hu, D. H. Yin et al., "Catalytic strategy of S-Adenosyl-L-homocysteine hydrolase: transition-state stabilization and the avoidance of abortive reactions," Biochemistry, vol. 42, no. 7, pp. 1900-1909, 2003.

[43] F. Cappello, E. C. de Macario, L. Marasà, G. Zummo, and A. J. Macario, "Hsp60 expression, new locations, functions and perspectives for cancer diagnosis and therapy," Cancer Biology \& Therapy, vol. 7, no. 6, pp. 801-809, 2008.

[44] D. Tondeleir, D. Vandamme, J. Vandekerckhove, C. Ampe, and A. Lambrechts, "Actin isoform expression patterns during mammalian development and in pathology: insights from mouse models," Cell Motility and the Cytoskeleton, vol. 66, no. 10, pp. 798-815, 2009.

[45] F. Ren, H. Wu, Y. Lei et al., "Quantitative proteomics identification of phosphoglycerate mutase 1 as a novel therapeutic target in hepatocellular carcinoma," Molecular Cancer, vol. 9, article 81, 2010.

[46] M. Nakamura, H. Morisawa, S. Imajoh-Ohmi, C. Takamura, H. Fukuda, and T. Toda, "Proteomic analysis of protein complexes in human SH-SY5Y neuroblastoma cells by using blue-native gel electrophoresis: an increase in lamin $\mathrm{A} / \mathrm{C}$ associated with heat shock protein 90 in response to 6-hydroxydopamine-induced oxidative stress," Experimental Gerontology, vol. 44, no. 6-7, pp. 375-382, 2009.

[47] H. P. Kim, D. Morse, and A. M. K. Choi, "Heat-shock proteins: new keys to the development of cytoprotective therapies," Expert Opinion on Therapeutic Targets, vol. 10, no. 5, pp. 759769, 2006.

[48] E. M. Karapanagiotou, K. Syrigos, and M. W. Saif, "Heat shock protein inhibitors and vaccines as new agents in cancer treatment," Expert Opinion on Investigational Drugs, vol. 18, no. 2, pp. 161-174, 2009.

[49] A. P. Kyriazis, W. B. McCombs, and A. A. Sandberg, "Establishment and characterization of human pancreatic adenocarcinoma cell line SW-1990 in tissue culture and the nude mouse," Cancer Research, vol. 43, no. 9, pp. 4393-4401, 1983.

[50] M. E. Madden and M. P. Sarras, "Morphological and biochemical characterization of a human pancreatic ductal cell line (PANC-1)," Pancreas, vol. 3, no. 5, pp. 512-528, 1988.

[51] S. Ishigaki, N. Hishikawa, J. I. Niwa et al., "Physical and functional interaction between dorfin and valosin-containing protein that are colocalized in ubiquitylated inclusions in neurodegenerative disorders," The Journal of Biological Chemistry, vol. 279, no. 49, pp. 51376-51385, 2004.

[52] K. E. Hung, V. Faca, K. Song et al., "Comprehensive proteome analysis of an Apc mouse model uncovers proteins associated with intestinal tumorigenesis," Cancer Prevention Research, vol. 2, no. 3, pp. 224-233, 2009.

[53] J. C. Ghosh, T. Dohi, H. K. Byoung, and D. C. Altieri, "Hsp60 regulation of tumor cell apoptosis," The Journal of Biological Chemistry, vol. 283, no. 8, pp. 5188-5194, 2008.
[54] T. Qi, J. Han, Y. Cui, M. Zong, X. Liu, and B. Zhu, "Comparative proteomic analysis for the detection of biomarkers in pancreatic ductal adenocarcinomas," Journal of Clinical Pathology, vol. 61, no. 1, pp. 49-58, 2008.

[55] K. Mehta, "Biological and therapeutic significance of tissue transglutaminase in pancreatic cancer," Amino Acids, vol. 36, no. 4, pp. 709-716, 2009.

[56] G. Di Giacomo, A. Lentini, S. Beninati, M. Piacentini, and C. Rodolfo, "In vivo evaluation of type 2 transglutaminase contribution to the metastasis formation in melanoma," Amino Acids, vol. 36, no. 4, pp. 717-724, 2009.

[57] N. Chen, W. Sun, X. Deng et al., "Quantitative proteome analysis of HCC cell lines with different metastatic potentials by SILAC," Proteomics, vol. 8, no. 23-24, pp. 5108-5118, 2008.

[58] T. Grewal, M. Koese, C. Rentero, and C. Enrich, "Annexin A6regulator of the EGFR/Ras signalling pathway and cholesterol homeostasis," International Journal of Biochemistry and Cell Biology, vol. 42, no. 5, pp. 580-584, 2010. 

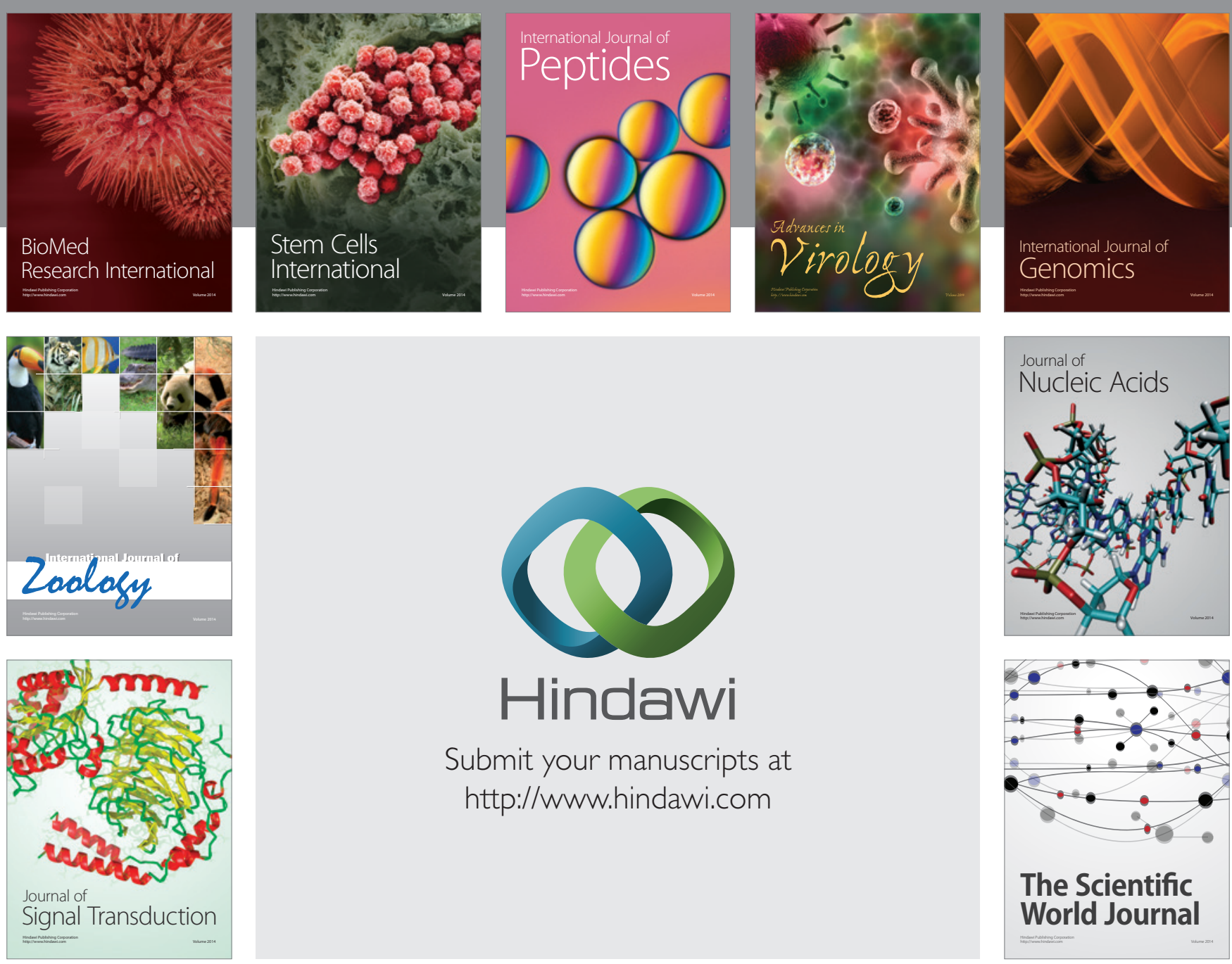

Submit your manuscripts at

http://www.hindawi.com
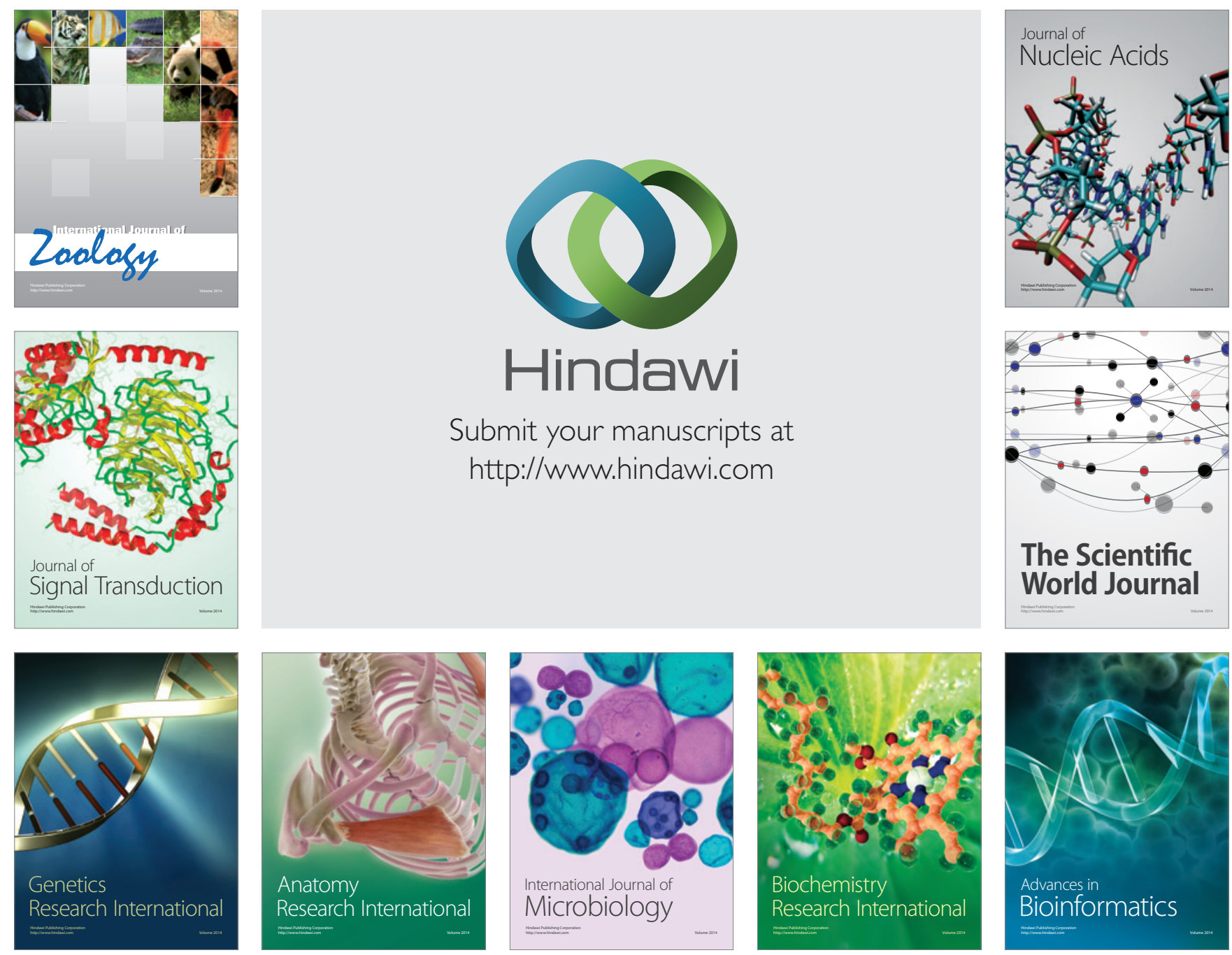

The Scientific World Journal
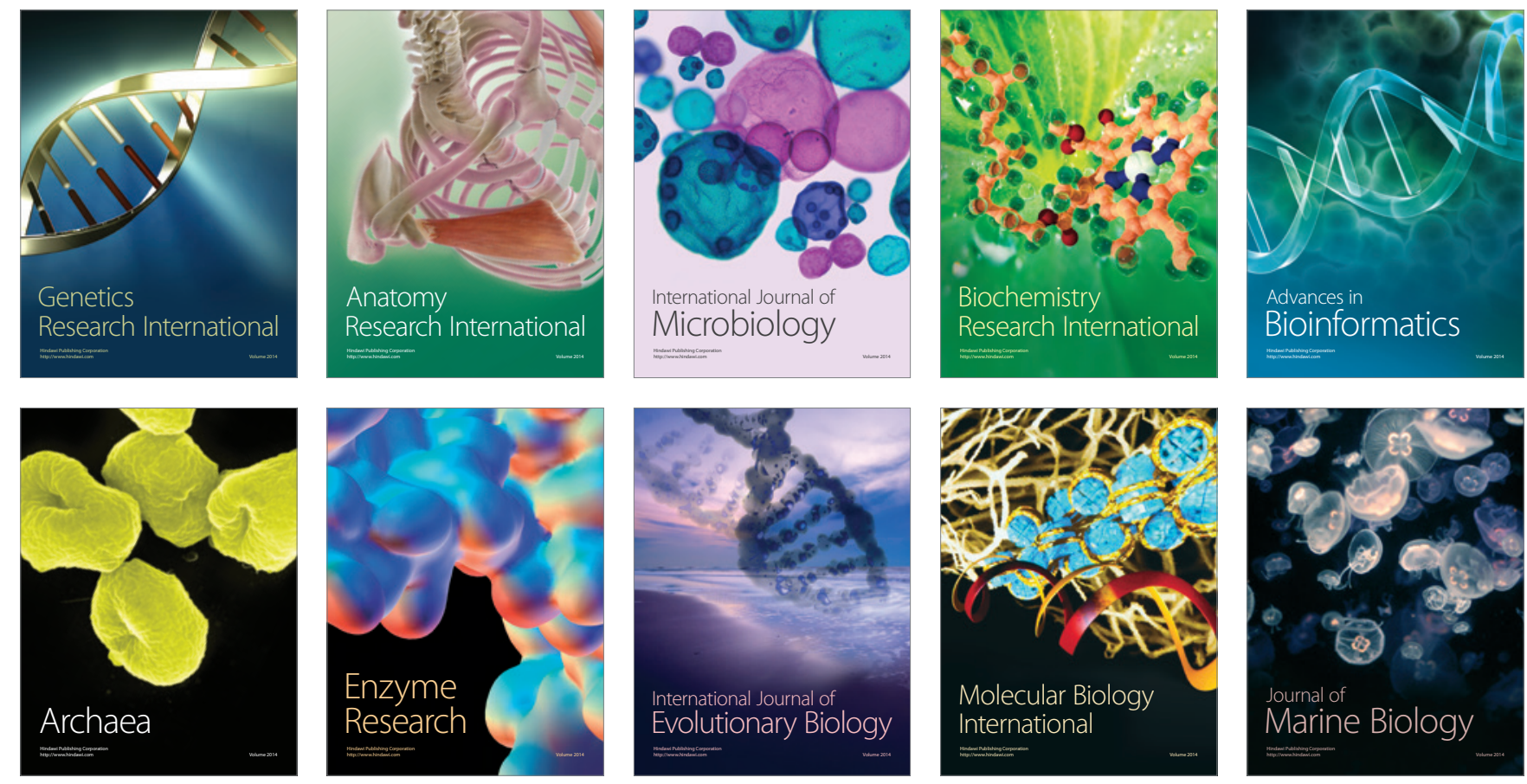